\title{
Empirical Model and Validation of Bar Formation in Sand Bed Channel
}

\author{
Duratul Ain Tholibon ${ }^{1}$, Junaidah Ariffin ${ }^{2}$, Jazuri Abdullah ${ }^{2}$, Ainamardia Nazarudin ${ }^{1}$, Nur Ain Mat Yusof ${ }^{1}$ and Dulina \\ Tholibon ${ }^{3}$ \\ ${ }^{1}$ Faculty of Civil Engineering, Universiti Teknologi MARA (UiTM), 26400 Jengka, Malaysia \\ ${ }^{2}$ Faculty of Civil Engineering,Universiti Teknologi MARA (UiTM), 40000 Shah Alam, Malaysia \\ ${ }^{3}$ Faculty of Mechanical Engineering, Universiti Kebangsaan Malaysia, 43600 Bangi, Malaysia
}

\begin{abstract}
Both present experimental and previous historical data were used to develop the empirical model. Generally, the aim of this study to establish an empirical model of bar formation from the present experimental data and selected historical data. Statistical techniques using Multiple Linear Regression Analysis were employed for empirical model development and the selection of bar formation parameters were done based on the works of previous investigators. Validation of the newly developed empirical model was done by using a different set of historical data from selected laboratory studies. Model development involved selection of parameters through review of established models, dimensional analysis to check on the homogeneity of the model and statistical analysis. Derived empirical model has been validated using a different set of data from previous studies. Analysis confirmed that the empirical model derived using linear regression technique depicts the highest discrepancy ratio accuracy of $90 \%$ with $\frac{\mathrm{D}}{\mathrm{d}_{\mathrm{s}}}$ and $\frac{\mathrm{B}}{\mathrm{D}}$ as the most significant parameters that promote bar height formation.
\end{abstract}

\section{Introduction}

Bars formation are present in most sand and gravel bed rivers and shows strong influence on flow and sediment transport processes and consequently on channel morphology [1] and as a fundamental sedimentary feature of braided rivers [2]. It is being observed in a field study that simple lobate unit bars occur with distinct downstream margins that may have avalanche faces, especially in the sand bed channel. Many data have been collected on the occurrence of bars in laboratory study to develop the empirical criteria for alternate bar formations and predictors for the equilibrium length and height of bars [3] [5]. Theoretically, a large number of linear studies that seek the conditions for incipient bar formation and linear growth rate under steady flow conditions has been developed.

Generally, the aim of this study to establish an empirical model of bar formation from the present experimental data and selected historical data. Statistical techniques using Multiple Linear Regression Analysis were employed for empirical model development and the selection of bar formation parameters were done based on the works of previous investigators. Validation of the newly developed empirical model was done by using a different set of historical data from selected laboratory studies.

\section{Multiple linear regression analysis}

In multiple linear correlation and regression, the additional independent variables denoted by $\mathrm{X}_{1}, \mathrm{X}_{2} \ldots \mathrm{X}_{\mathrm{k}}$ help to better explain or predict the dependent variables (Y). The general linear model (First order multiple regression model) are as follows;

$$
\mathrm{Y}=\beta \mathrm{o}+\beta_{1} \mathrm{X}_{1}+\beta_{2} \mathrm{X}_{2}+\beta_{3} \mathrm{X}_{3}+\ldots+\beta_{\mathrm{k}} \mathrm{X}_{\mathrm{k}}+\varepsilon
$$

or

$$
\mathrm{Y}=\mathrm{A}+\mathrm{B}_{1} \mathrm{X}_{1}+\mathrm{B}_{2} \mathrm{X}_{2}+\mathrm{B}_{3} \mathrm{X}_{3}+\ldots \mathrm{B}_{\mathrm{k}} \mathrm{X}_{\mathrm{k}}+\varepsilon
$$

where;

$\mathrm{Y}=$ dependent variable

$\mathrm{X}_{1}, \mathrm{X}_{2}, \mathrm{X}_{3}, \ldots, \mathrm{X}_{\mathrm{K}}=$ dependent variables

$\beta_{0} / A=$ intercept, the value of $Y$ when all the $X$ 's are zero

$\beta_{j} / B_{j}=$ amount by which $Y$ changes when that particular $\mathrm{X}_{\mathrm{j}}$ increase by one unit, with the values of all other independent variables held constant.

$\varepsilon=$ random error term

If the multiple linear regression is estimated using sample data, the estimated regression equation is written as

$$
\widehat{Y}=\widehat{\beta}_{\mathrm{o}}+\widehat{\beta}_{1} \mathrm{X}_{1}+\widehat{\beta}_{2} \mathrm{X}_{2}+\widehat{\beta}_{3} \mathrm{X}_{3}+\ldots+\widehat{\beta}_{\mathrm{k}} \mathrm{X}_{\mathrm{k}}
$$




$$
\widehat{Y}=a+b_{1} X_{1}+b_{2} X_{2}+b_{3} X_{3}+\ldots+b_{k} X_{k}
$$

where $\hat{Y}$ is the estimated value for $Y$.

The assumptions of the multiple linear regression method are [6].

(a) The mean of the probability distribution of $\varepsilon$ is zero, that is $\mathrm{E}(\varepsilon)=0$

(b) The errors must be normally distributed and have a constant variance, $\sigma_{\varepsilon}^{2}$

(c) The independent variables are not linearly related, but they can have a nonlinear relationship. High correlation among independent variables would result to the existence of multicollinearity.

(d) There is no linear association between the random error term, $\varepsilon$ and each independent variable.

\section{Methodology}

Selections of the bar formation parameters are based on the review done by previous researcher and through dimensionless analysis. In this analysis, six dimensionless independent parameters namely ratio of grain size $\left(\frac{d_{s}}{R S}\right)$, ratio of velocity to shear velocity $\left(\frac{V}{U *}\right)$, ratio of channel width to grain size $\left(\frac{B}{d_{s}}\right)$, ratio of channel depth to grain size $\left(\frac{D}{d_{s}}\right)$, Shields stress $\left(\tau^{*}\right)$, and ratio of width to depth $\left(\frac{B}{D}\right)$ were chosen and analyzed on their correlations with the dependent variable, ratio of bar height to grain size $\left(\frac{H_{B}}{d_{s}}\right)$. Multiple linear and nonlinear regression technique used to investigate the relationship between the dependent variable and independent variables.

The statistical technique was employed in the analysis, namely multiple linear regression. The new empirical model will be developed using data from the present experimental study and selected data from previous researchers. The newly developed empirical model will be validated using a different set of data from previous investigators. The procedure involved in the analyses are as follows;

(a) Selection of the data from the previous researchers.

(b) Derivation of the empirical models through a various combination of the variables using multiple linear regression techniques.

(c) Validation of the newly developed empirical model using selected data from previous researchers.

There were a total of ten experimental works regarding bar height formation, including the present study that gives a total of 189 data. These data were being classified into two groups; data that collected during the experimental works and data of independent parameters that computed using the collected data. Selection of data to be use in model development and model validation were depend on the range of flow rates. For the data of present study, the recorded flow rates were the initial flow rates imposed to the channel while the recorded data for velocity, channel width and flow depth were for final condition. The grains size and slope of the channel were assumed constant for all experimental run. Velocity recorded is below the critical velocity, as this is due to resistance of bed configuration of bar formation at the final measurement. The data were tabulated in Table 1.

Table 1. Range of hydraulics and sediment characteristics data used in the analyses

\begin{tabular}{|c|c|c|c|c|c|c|c|c|c|}
\hline \multirow[t]{3}{*}{ No. } & \multirow[t]{3}{*}{ Researcher } & \multirow{3}{*}{$\begin{array}{c}\text { No of } \\
\text { Data }\end{array}$} & \multicolumn{6}{|c|}{ Independent Parameters } & \multirow{3}{*}{$\begin{array}{c}\begin{array}{c}\text { Dependent } \\
\text { Parameter }\end{array} \\
\frac{H_{B}}{d_{S}}\end{array}$} \\
\hline & & & $d_{S}$ & $V$ & $B$ & $D$ & $\tau_{*}$ & $B$ & \\
\hline & & & $\overline{R S}$ & $\overline{U_{*}}$ & $d s$ & $d s$ & & $D$ & \\
\hline 1 & Present study & 12 & $7.49-37.95$ & $5.05-9.1$ & $173.913-347.826$ & $4.35-26.09$ & $0.016-0.08$ & $3.571-21.053$ & $66.09-106.96$ \\
\hline 2 & Kinoshita (1961) & 26 & $2.06-10.6$ & $4.54-7.93$ & $77.647-347.368$ & $3.76-14.47$ & $0.06-0.29$ & $8.2-33.85$ & $3.53-36.84$ \\
\hline 3 & Yoshino (1967) & 38 & $1.45-13.66$ & $5.46-10.74$ & $65.22-688.89$ & $5.35-46.67$ & $0.04-0.42$ & $3.53-30.1$ & $2.43-55.78$ \\
\hline 4 & Fujita (1980) & 6 & $2.93-10.85$ & $7.7-9.32$ & 555.556 & $12.73-25.45$ & $0.06-0.2$ & $21.83-43.65$ & $26.57-45.05$ \\
\hline 5 & Ikeda (1984) & 29 & $6.73-12.29$ & $6.36-9.24$ & 246.15 & $7.54-27.54$ & $0.05-0.09$ & $8.94-32.65$ & $5-21.54$ \\
\hline 6 & Fujita & 7 & $4.25-13.65$ & $7.95-11.08$ & $340.91-2272.73$ & $14.32-49.09$ & $0.04-0.14$ & $20-48.19$ & $15.25-83.52$ \\
\hline & Muramoto (1985) & & & & & & & & \\
\hline 7 & Tubino (1991) & 6 & $6.71-7.67$ & $8.76-9.09$ & 545.45 & $20-23.09$ & $0.08-0.09$ & $23.62-27.27$ & $13.64-35.18$ \\
\hline 8 & $\begin{array}{l}\text { Garcia \& Nino } \\
(1993)\end{array}$ & 37 & $4.92-12.76$ & $8.05-10.62$ & 754.72 & $14.53-43.77$ & $0.05-0.12$ & $8.62-26.08$ & $22.64-89.30$ \\
\hline 9 & $\begin{array}{l}\text { Rahman et al. } \\
(1996)\end{array}$ & 17 & $14.94-20.31$ & $7.03-9.86$ & 98.59 & $7.04-24.65$ & $0.03-0.04$ & $4-14$ & $3.76-26.25$ \\
\hline 10 & Lanzoni (2000a) & 11 & $17.63-44.54$ & $8.3-10.5$ & 312.5 & $6.88-17.29$ & $0.014-0.034$ & $18.07-45.45$ & $8.33-17.71$ \\
\hline
\end{tabular}

\section{Results and discussions}

A total of 41 linear and nonlinear regression equations were derived. Accuracy of the equations is measured based on 3 elements, (i) discrepancy ratio, (ii) statistical test analysis and (iii) graphical analysis. Discrepancy ratio is the ratio of the predicted values to the measured values and these values are deemed accurate if they lie within 0.5-2.0 limit. The statistical test is used to further quantify the accuracy of the model. A model is deemed significant if the collinearity statistics give values of tolerance higher than 0.1 and VIF lower than 10. Visual 
analysis through graphs representation is used to confirm the trends and accuracy of the prediction. The accuracy can be evaluated from the distribution pattern of the data. Homoscedastic scatter with high positive correlation signify good agreement of the predicted to observed values.

Based on these three elements, linear equation is seemed to perform better than nonlinear models for all sets of data from the present study, Kinoshita, 1961; Yoshino, 1967; Fujita, 1980; Ikeda, 1984; Lanzoni, 2000a. [7]-[9], [3], [10].The derived model using linear regression have established two dimensionless parameters namely $\frac{D}{d_{s}}$ and $\frac{B}{D}$ with the other parameters of $\frac{d_{s}}{R S}, \frac{V}{U^{*}}, \frac{B}{d_{s}}$ and $\tau^{*}$ excluded. The prediction accuracy for this linear regression model is $90 \%$ on data from the present experimental study and previous researchers. Summary of the performance of derived empirical models using linear and nonlinear regression method with the respective value of $\mathrm{R}^{2}$ and discrepancy ratio are shown in Table 2.

Table 2. Performance of derived models in this study

\begin{tabular}{|l|l|l|l|}
\hline Method & \multicolumn{1}{|c|}{ Equation } & $\mathrm{R}^{2}$ & $\begin{array}{l}\mathrm{D} . \mathrm{R} \\
(0.5-2.0)(\%)\end{array}$ \\
\hline Linear & $\frac{\mathrm{H}_{\mathrm{B}}}{\mathrm{d}_{\mathrm{s}}}=-3.35+1.63 \frac{\mathrm{D}}{\mathrm{d}_{\mathrm{s}}}+0.17 \frac{\mathrm{B}}{\mathrm{D}}$ & 0.17 & 90 \\
\hline Non linear & $\frac{\mathrm{H}_{\mathrm{B}}}{\mathrm{d}_{\mathrm{s}}}=0.429\left(\frac{\mathrm{B}}{\mathrm{d}_{\mathrm{s}}}\right)^{0.71}(\tau *)^{-0.035}$ & 0.50 & 88 \\
\hline
\end{tabular}

\subsection{Validation of empirical models}

An attempt was also made to validate all the derived models for other sets of data from previous studies $[5 ; 11$; 12; and 13] and the results are shown in Table 3. Analysis confirms that newly derived empirical model prediction gives satisfactory performance when validated on data from previous researchers. The results from [5] indicates the most accurate prediction as the value of discrepancy ratio of $100 \%$. This is evident from the distribution pattern of the data of each researcher that lies within the acceptable limit as shown in Fig. 1.

Table 3. Validation of derived models on data by previous studies

\begin{tabular}{llllll}
\hline Method & \multicolumn{4}{l}{ Discrepancy ratio $(0.5-2.0)(\%)$} \\
\cline { 2 - 6 } & {$[12]$} & {$[5]$} & {$[13]$} & {$[11]$} & Combine \\
& {$[6$ data $]$} & {$[7$ data $]$} & {$[37$ data $]$} & {$[17$ data $]$} & {$[67$ data $]$} \\
\hline Linear & 67 & 100 & 92 & 88 & 90 \\
Non linear & 67 & 100 & 95 & 76 & 88 \\
\hline
\end{tabular}

Non-linear equation gives significant contribution that shows the highest $\mathrm{R}^{2}$ value of 0.5 as compared to linear regression method. However, there is clear indication that distribution pattern of data in which the scatter plot shown in Fig. 1 shows well distribution pattern for linear Equation as compared to nonlinear. Thus linear equation derived using linear regression technique is the best derived empirical model with $90 \%$ accuracy with $\frac{D}{d_{s}}$ and $\frac{B}{D}$ as the most significant parameters that promote bar height formation. This indicates the findings of the present study corroborate the previous work done by [3].

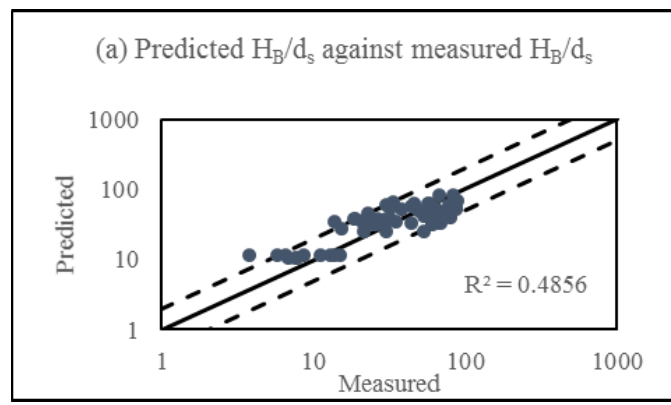

Figure 1. Graph of validation using linear regression method.

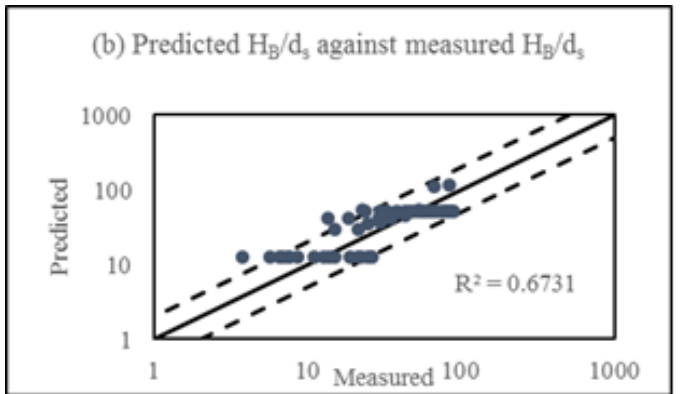

Figure 2. Graph of validation using non-linear regression method.

\section{Conclusion}

New empirical model to predict the bar height formation in a sand bed channel have been developed using experimental data from the present study and selected sets of historical data from previous investigators. Techniques used in developing the equation are the Multiple Linear Regression and Nonlinear Regression. Derived empirical model has been validated using a different set of data from previous studies. Analysis confirmed that the empirical model derived using linear regression method gave the best prediction accuracy of 
$90 \%$ with $\frac{D}{d_{s}}$ and $\frac{B}{D}$ as the most significant parameters that promote bar height formation.

\section{Acknowledgement}

The authors gratefully acknowledge Faculty of Civil Engineering, Universiti Teknologi MARA, Shah Alam for the facility provided. This research grant was provided by the Ministry of Higher Education Malaysia (600-RMI/RAGS 5/3 (176/2014)) and the Research Management Institute (RMI) of Universiti Teknologi MARA, Shah Alam, Malaysia.

\section{References}

1. P. J. Whiting and W. E. Dietrich. Convective accelerations and boundary shear stress over a channel bar. Water Resources Research. 27, 783-796. (1991).

2. P. Ashmore. Morphology and dynamics of braided rivers. Treatise on Geomorphology, 9, 289-312. (2013).

3. S. Ikeda. Prediction of alternate bar wavelength and height. Journal Hydraulic Engineering, 110, 371386. (1984).

4. M.N.R. Jaeggi. Formation and effects of alternate bars. Journal Hydraulics Engineer, 110, 142-156. (1984).
5. Y. Fujita and Y. Muramoto. Studies on the process of development of alternate bars. Bulletin of the Disaster Prevention Research Institute, 35, 55-86. (1985).

6. S. Landau and B.S. Everitt. A handbook of statistical analyses using SPSS. Chapman \& Hall/CRC Press LLC. (2004).

7. R. Kinoshita. Investigation of channel deformation in Ishikari River. Report of Bureau of Resources, Department of Science and Technology, Japan, 1174. (in Japanese). (1961).

8. F. Yoshino. Study on bed forms. Collected Papers, Department of Civil Engineering, University of Tokyo, Tokyo, Japan, 4, 165-176. (in Japanese). (1967).

9. Y. Fujita. Fundamental study on channel changes in alluvial rivers. Kyoto University, Japan, 1-210. (in Japanese). (1980).

10. S. Lanzoni. Experiments on bar formation in a straight flume: 1. Uniform sediment. Water Resources Research, 36, 3337-3349. (2000).

11. M. M. Rahman, N. Nagata, T. Hosoda, and Y Muramoto. Experimental study on morphological process of meandering channel with bank erosion. Annual Journal of Hydraulic Engineering, 40, $947-$ 952. (1996).

12. M. Tubino. Growth of alternate bars in unsteady flow. Water Resources Research, 27, 37-52. (1991).

13. M. Garcia and Y. Nino. Dynamics of sediment bars in straight and meandering channels: experiments on the resonance phenomenon. Journal Hydraulics Research, 31, 739-761. (1993). 